\title{
Marketing Politik Calon Walikota Padang pada Pilkada Serentak Juni 2018
}

\author{
Indah Fajar Lestari, Al Rafni \\ Program Studi Pendidikan Pancasila dan Kewarganegaraan \\ Universitas Negeri Padang \\ Email : indahfajarlestari195@gmail.com
}

\section{ABSTRAK}

Pelaksanaan Pilkada Kota Padang Juni 2018 yang diikuti oleh calon incumbent memiliki cara-cara marketing politik yang unik. Hal ini karena calon Walikota Padang merupakan pasangan incumbent yang memilih maju dengan pasangannya masing-masing sehingga diperlukan marketing yang berbeda untuk memenangkan Pilkada. Penelitian ini akan membandingkan marketing politik yang dilakukan kedua calon Walikota Padang terkait 4 aspek yaitu product political marketing, place political marketing, prise political marketing dan promotion political marketing. Tujuan penelitian ialah untuk mengkomparasikan marketing politik yang dilakukan oleh kedua pasang calon Walikota Padang yaitu EmzalmiDesri Ayunda dan Mahyeldi-Hendri Septa dalam Pilkada serentak Juni 2018. Jenis penelitian ini adalah penelitian komparatif dengan pendekatan kualitatif. Pemilihan informan dilakukan dengan teknik Purposive Sampling. Jenis data terdiri dari data primer dan data sekunder, dikumpulkan melalui wawancara dan studi dokumentasi. Uji keabsahaan data menggunakan triangulasi sumber. Analisis data dilakukan melalui pengumpulan data, reduksi data, penyajian data dan penarikan kesimpulan. Hasil penelitian menunjukan bahwa marketing politik yang dilakukan pasangan Mahyeldi-Hendri Septa lebih baik dari pasangan Emzalmi-Desri Ayunda setelah dibandingkan dari segi, price,place dan promotion politic marketing. Keberhasilan pasangan Mahyeldi-Hendri Septa dalam memasarkan product politik dengan memanfaatkan ketokohan dalma masyarakat, penggunaan dana dan tempat kampanye dengan baik, serta promosi yang dilakukan dengan baik melalui media atau bertemu langsung dengan masyarakat berhasil mengantarkan pasangan menjadi Walikota dan Wakil Walikota Padang pada Pilkada Serentak Juni 2018.

Kata Kunci: Pilkada Walikota Padang, Product; Price; Place; Promotian Political Marketing

\section{ABSTRACT}

Padang local elections in June 2018, followed by incumbent candidates have ways a unique political marketing. This is because the candidate for mayor of Padang is incumbent couples who choose advanced with their respective spouses requiring different marketing to win elections. This study will compare political marketing by the two candidates for mayor of Padang 4 aspects related to political marketing product, place political marketing, political marketing and promotion prize of political marketing. The aim of the research was to compare political marketing done by the two pairs of candidates for mayor of Padang that EmzalmiDesri Ayunda and Mahyeldi-Hendri Septa simultaneous elections in June 2018. The research 
is a comparative study with a qualitative approach. Selection of informants with purposive sampling technique. This type of data consists of primary data and secondary data, collected through interviews and documentation study. Keabsahaan test data using triangulation. Data analysis was performed through data collection, data reduction, data presentation and conclusion. The results showed that political marketing that made the couple MahyeldiHendri Septa better than a couple Emzalmi-Desri Ayunda after comparison of terms, price, place and promotion marketing politics. Mahyeldi pair-Hendri success in marketing the product Septa political utilizing dalma public persona, the use of funds and the campaign well.

Keywords : Simultaneous Elections, Padang's Mayor, politic marketing, campaign

This work is licensed under the Creative Commons Attribution-ShareAlike 4.0 International License. (C2019 by author and Universitas Negeri Padang.

\section{PENDAHULUAN}

Pelaksanaan Pilkada Kota Padang Juni 2018 yang diikuti oleh calon incumbent memiliki cara-cara marketing politik yang unik. Hal ini karena calon Walikota Padang merupakan pasangan incumbent yang memilih maju dengan pasangannya masing-masing sehingga diperlukan marketing yang berbeda untuk memenangkan Pilkada. Pilkada Kota Padang diikuti oleh 2 pasang calon yaitu pasangan Emzalmi-Desri Ayunda dan Pasangan Mahyeldi Hendri Septa. Kedua pasang calon didukung oleh koalisi partai politik. Pasangan Emzalmi-Desri didukung oleh koalisi besar yang memiliki lebih dari 30 kursi di DPRD Kota Padang, sedangkan pasangan Mahyeldi-Hedri Septa didukung oleh dua Partai berideologi islam memiliki 11 kursi di DPRD Kota Padang. Jika kemenangan Pilkada cukup ditentukan oleh besar dan banyaknya Partai Pendukung, maka Pasangan Mahyeldi-Hendri Septa sudah pasti kalah, namun realnya pasangan ini berhasil memenangkan Pilkada.
Jika dilihat dari latar belakang kandidat, pasangan nomor urut satu Emzalmi merupakan wakil walikota aktif periode 2013-2018, dan sudah lama menjabat dibirokrat, berpasangan dengan Desri Ayunda yang merupakan seorang profesional dan lama bekerja di PT Semen Padang. Pasangan nomor urut dua, Mahyeldi Ansharullah adalah Walikota aktif periode 2013-2018, politisi Partai Keadilan Sejahtera dan dipandang sebagai tokoh agama yang baik, berpasangan dengan Hendri Septa seorang politisi Partai Amanat Nasional, pernah menjabat sebagai anggota DPRD Kota Padang.

Kedua calon Walikota Padang merupakan pasangan Walikota dan Wakil Walikota Padang periode 20132018. Pada periode kepemimpinannya dianggap mampu memberikan kemajuan bagi Kota Padang, Seperti yang di katakan Sofia Lora (warga Kota Padang), dan pemberitaan gosumbar.com pada sabtu, 27 Februari 2016 bahwa keberhasilan pembangunan Kota Padang dapat terlihat melalui adanya pembangunan Pasar Raya Padang, kawasan wisata 
Pantai Padang dan berbagai insfrastruktur lainnya. Kemajuan tersebut juga mendapat penilaian yang baik dari kalangan masyarakat, sehingga dianggap sebagai pemimpin yang mampu memberikan perubahan bagi Kota Padang.

Pada Pilkada serentak 2018 baik Walikota maupun Wakil Walikota memilih maju dengan pasangannya masing-masing. Hal ini tentu memerlukan marketing politik yang berbeda dengan Pilkada sebelumnya. Berbagai marketing politik yang unik dilakukan oleh kedua pasang calon dalam menarik simpati rakyat. Salah satu marketing politik yang dilakukan pasangan Mahyeldi- Hendri Septa ialah melalui pendekatan pada kelompok-kelompok majelis taklim, mendekati kaum muda melalui kegiatan seperti seminar-seminar, mendekati masyarakat melalui berbagai kegiatan, misalnya dengan menghadiri jalan santai, buka puasa bersama, dan sebagainya. Sedangkan pasangan Emzalmi-Desri melakukan marketing politik diantaranya melalui pendekatan dengan tokoh-tokoh masyarakat seperti tokoh-tokoh adat.

Selama masa kampanye, pasangan Mahyeldi-Hendri Septa banyak melakukan pendekatan dengan mengintensifkan pertemuan dengan majelis-majelis taklim yang ada di Kota Padang, melakukan berbagai kegiatan yang mengikutsertakan masyarakat banyak. Sedangkan pasangan Emzalmi-Desri cendrung melakukan pendekatan dengan kalangan birokrat dan kalangan pengusaha. Jika dilihat dari latar belakang kandidat, pasangan Mahyeldi-Hendri Septa sama-sama berasal dari publik figur yang dikenal masyarakat karena pernah menjabat sebagai Walikota dan anggota DPRD. Sedangkan pasangan Emzalmi-Desri berasal dari kalangan birokrat dan pengusaha.

Pilkada serentak Juni 2018 dimenangkan oleh pasangan nomor urut 2 yaitu Mahyeldi-Hendri septa. Walaupun demikian tetap penting dilakukan pengkajian terhadap marketing politik yang dilakukan oleh kedua pasang calon, mengingat kedua calon walikota berasal dari pasangan walikota dan wakil walikota periode sebelumnya dan sama-sama sudah dikenal baik oleh masyarakat melalui keberhasilan pembangunan Kota Padang yang telah dilakukan, selain itu diprediksi akan ada marketing politik yang berbeda antara kedua pasnagan calon dan tim sukses sebagai akibat pecahnya kubu walikota dan wakil walikota sebelumnya dengan memilih maju dengan pasanagn masing-masing, sehingga marketing politik yang dilakukan akan berbeda dengan marketing politik pada Pilkada tahun 2013 yang memenangkan pasnagan Mahyeldi-Hendri Septa. Dengan demikian tujuan penelitian ini adalah untuk mengetahui marketing politik yang dilakukan pada Pilkada Kota Padang Juni 2018. Marketing politik akan diteliti menggunakan empat elemen penting marketing politik yaitu Product, Price, place dan Promotion politic marketing yang dilakukan setiap pasang calon maupun tim suksesnya dalam merebut simpati masyarakat Kota Padang.

\section{METODE PENELITIAN}

Jenis penelitian ini adalah penelitian komparatif mengunakan pendekatan Kualitatif. Penelitian komparatif merupakan jenis penelitian 
untuk membandingkan aspek-aspek yang menjadi kajian penelitian. Menurut Sugiyono (2013), penelitian komparatif adalah sebuah penelitian yang memiliki sifat membandingkan. Lokasi penelitian ialah Kota Padang, Sumatera Barat. Jenis data yang digunakan ialah data primer dan data sekunder dengan pengumpulan data melalui wawancara, studi dokumentasi. Teknik ananlisis keabsahan data melalui triangulasi sumber dan member check. Teknik analisis data menggunakan reduksi data, sajian data, dan penarikan kesimpulan.

\section{HASIL DAN PEMBAHASAN}

Marketing adalah sesuatu yang penting dalam menghadapi suatu persaingan, dimana semua berkompetisi untuk mendapatkan prestasi tertentu. Ketika terjadi rivalitas yang tinggi maka semakin tinggi pula kebutuhan akan marketing sebagai alat untuk memenangkan persaingan. Strategi marketing politik adalah cara yang tepat untuk memenangkan sebuah kontestasi pemilihan umum. Menurt Firmanzah (2008) dalam Damsar (2012:235) Marketing politik ialah metode yang digunakan untuk meningkatkan pemahaman tentang masyarakat, dan ini juga berguna dalam membuat produk politik yang akan ditawarkan pada masyarakat. Begitu juga dengan marketing politik yang dilakukan oleh calon Walikota dan Wakil Walikota Padang pasangan urut Emzalmi-Desri Ayunda dan Pasangan MahyeldiHendri Septa pada pilkada serentak Juni 2018. Dalam Damsar (2012:236), dijelaskan paling sedikit terdapat empat elemen Marketing Politik yang penting diperhatikan, diantaranya sebagai berikut :

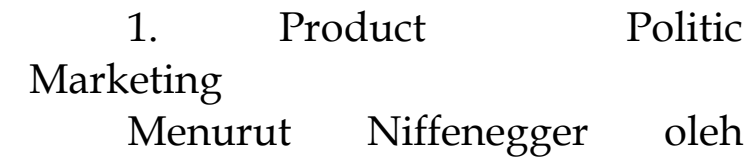
Firmanzah (2008:200), politik adalah sesuatu hal yang dapat diperoleh dan dinikmati oleh pemilih setelah dilaksanakannya pemilu atau terpilihnya seorang kandidat. Produk politik tersebut terdiri dari party platform (platform partai), past record (rekaman jejak/lampau), personal characteristic (karakteristik individual). Terkait hal tersebut Nurman,S dan Al Rafni (2005) menyatakan bahwa strategi setiap partai politik dalam memenangkan kontestasi politik sangat ditentukan oleh ideologi dan platform masingmasing dimana partai politik tersebut menarik simpati masyarakat pemilihnya. Hal ini yang dilakukan pasangan calon dan tim sukses yaitu dengan memanfaatkan nama besar partai pendukungnya dalam menarik simpati pemilih. Pentingnya ideologi partai politik dalam hal ini juga dijelaskan Lili Ramli, (2011) bahwa keberadaan ideologi dalam sebuah partai juga menjadi pedoman nilai dalam melakukan program dan aktifitas kerja politik merupakan sesuatu hal juga penting.

Selain itu produk politik yang juga berpengaruh dalam memenangkan suatu Pilkada juga diungkapkan oleh Rianto Psida,dkk (2018), bahwa "Faktor kepribadian berkaitan dengan figur tokoh sebagaimana penilaian orang lain terhadapnya, pengaruh figur dalam membentuk penilaian pribadi seseorang, karena figur menanamkan mindset bahwa inilah figur yang baik untuk jadi pemimpin". Titin Purwanigsih (2017), juga mengungkapkan "Modal sosial adalah 
Volume 1 No. 32018

salah satu komponen dalam memobilitas massa, sehingga keduanya (kandidat dan massa) saling mendapatkan keuntungan untuk kemajuan bersama".

\section{Place Politic Marketing}

Place politic marketing meliputi aksesibilitas dan letak posisi dari produk terhadap komsumen. Aksesibilitas produk berupa ketepatan media dan alat peraga agar mudah dilihat dan dipahami oleh konsumen. Selain itu posisi produk politik harus disesuaikan dengan tempat dan strata sosial pemilih. Hal ini dilakukan guna menarik simpati masyarakat pemilih. Yoga Swasono (2017) dalam skripsinya menyatakan bahwa media massa memiliki peranan yang penting dalam meningkatkan keberhasilan kampanye yang dilakukan. Hal ini tidak hanya mampu mempengaruhi individu juga individu lain untuk mengumpulkan suara. Pada pilkada Kota Padang kedua pasang kandidat juga memanfaatkan media dengan baik selama masa kampanye.

Selain itu pasangan EmzalmiDesri Ayunda juga melakukan pendekatan ke berbagai kalangan masyarakat seperti mendekati masyarakat dengan pendekatan kekerabatan memanfaatkan masyarakat Minangkabau yang cenderung memilih pemimpin yang dekat dengan mereka seperti satu suku atau satu daerah, mendekati generasi muda dengan memberikan support diberbagai kegiatan pemuda. Sedangkan pasangan MahyeldiHendri Septa melakukan pendekatan pada masyarakat dengan mengenali latar belakang masyarakat dengan baik, seperti mendekati generasi muda dengan melihat hobi dan kegiatan yang mereka sukai, kemudian ikut bergabung dengan kegiatannya seperti main bola bersama, membenahi karang taruna dan menawarkan program kampung pemuda. Pada masyarakat menengah kebawah dilakukan pendekatan dengan menawarkan fasilitas seperti perbaikan jalan bagi daerah yang membutuhkan, bantuan dana usaha, jaminan kesehatan dan sebagainya.

3. Price Politic marketing

Menurut Niffenegger oleh Firmanzah (2008:205), price (harga) dalam marketing politik meliputi harga ekonomi, harga politik, harga citra dan harga psikologis. Hal ini juga sesuai dengan yang disampaikan Gustiar Hamonangan (2017), bahwa "Secara konseptual calon kepala daerah untuk dapat mampu memenangkan pilkada langsung dengan memiliki tiga modal utama yaitu: modal politik (political capital), modal sosial (Social capital) dan modal ekonomi (ekonomical capital)". Titin Purwaningsih (2017), juga menyatakan bahwa "image (pencitraan) seseorang tidak tumbuh dalam waktu singkat, image bisa diciptakan dan hilang, sehingga perlua dibuat sedemikian rupa dan melekat pada diri kandidat dan tertanam baik dalam benak masyarakat".

Kedua pasang calon Walikota Padang sama-sama menggunakan dana kampanye kisaran 3-4 milyar, selama masa kampanye keduanya juga mengedepankan rekam jejak selama berkiprah di Kota Padang. Pasangan Emzalmi-Desri Ayunda mengedepankan rekam jejak kandidat sebagai birokrat dan profesional yang sudah lama mengabdi di Kota Padang. Sedangkan pasangan MahyeldiHendri Septa mengedepankan rekam jejak sebagai politisi yang pernah 
memenangkan berbagai peilu dan pilkada, citra sebagai tokoh yang dekat dengan masyarakat, memiliki sifat yang ramah, sederhana, akrab dengan masyarakat serta konsisten dengan janji. Disamping itu juga mengemukakan keberhasilan yang sudah dicapai walikota Padang selama ini.

4. Promotion Politic marketing

Pasangan Emzalmi-Desri Ayunda dan pasangan MahyeldiHendri Septa sama-sama memanfaatkan berbagai media massa dalam merebut simpati rakyat. Selama masa kampanye kedua pasang calon dan tim sukses banyak mempromosikan diri melalui media sosial seperti WhastApp, twiter, facebook, instagram dan sebagainnya, selain itu juga memanfaatkan media cetak, televisi dan media online lainnya. Hal ini karena banyaknya masyarakat yang menggunakan media tersebut sehingga menjadi cara yang tepat untuk meningkatkan citra calon melalui media. Dudi Rustandi (2014), menjelaskan bahwa "Jalan yang efektif untuk menyampaikan pesan-pesan politik dalam membangun citra dan reputasi ialah melalui berbagai media, misalnya televisi yang populer dalam pencitraan merek melalui iklan dan publikasi".

Selain itu, Yoga Swasono (2017) dalam skripsinya menyatakan bahwa, "Alat peraga kampanye adalah media yang selalu ada dan banyak digunakan dalam setiap pemilu dan Pilkada di Indonesia, dapat berbentuk umbulumbul, spanduk, bendera, stiker, pster, giant banner, poster, buklet, dan sebagainya, yang berisikan visi, misi, program pasangan calon, simbol- simbol dan tanda gambar pasangan calon."

Selama masa kampanye segala upaya dilakukan kedua pasang calon dalam menarik simpati masyarakat seperti mempromosikan diri melalui berbagai media yang ada, memasang dan mendistribusikan alat peraga kampanye kepada masyarakat, serta melakukan pendekatan dengan masyarakat dengan berbagai cara. Seperti yang dilakukan pasangan Emzalmi-Desri Ayunda yang mendekati masyarakat melalui pendekatan kekerabatan, walaupun dizaman sekarang hal seperti itu sudah kurang mendapat perhatian, selain itu melakukan pendekatan kepada anak muda dengan cara memberikan suport untuk berbagai kegiatannya. Sedangkan pasangan mahyeldiHendri Septa melakukan pendekatan pada semua kalangan masyarakat menyesuaikan kondisi masyarakat, misalnya menarik simpati pemuda dengan ikut berolahraga bersama, membenahi karang taruna, memberikan pembelajaran dan merencanakan Program kampung Pemuda (Pusat kegiatan pemuda) untuk olahraga, seni atau usaha. Pendekatan kepada PNS dengan menjanjikan untuk memberikan jaminan hak dengan tidak menambah kewajibannya, sedangkan untuk masyarakat menengah kebawah dengan menjanjikan adanya perbaikan jalan, kemudahan urusan dan perizinan, bantuan udaha dan sebagainya.

Berikut ini akan dijabarkan tabel yang mengkomparasikan marketing politik yang dilakukan oleh kedua pasang calon walikota Padang berdasarkan persamaan dan perbedaan, serta kelebihan dan 
kelemahan marketing politik yang dilakukan selama Pilkada Kota Padang Juni 2018.

Tabel 1

Kelemahan dan Kelebihan Marketing Politik Calon Walikota

\begin{tabular}{|c|c|c|c|c|}
\hline \multirow{2}{*}{$\begin{array}{l}\mathrm{N} \\
\mathrm{O}\end{array}$} & \multirow{2}{*}{$\begin{array}{l}\text { Indi } \\
\text { kato } \\
\text { r } \\
\text { Pem } \\
\text { beda }\end{array}$} & \multirow{2}{*}{$\begin{array}{c}\text { Persamaa } \\
n\end{array}$} & \multicolumn{2}{|c|}{ Perbedaan } \\
\hline & & & $\begin{array}{c}\text { Pasangan } \\
\text { Emzalmi- } \\
\text { Desri } \\
\text { Ayunda }\end{array}$ & $\begin{array}{c}\text { Pasangan } \\
\text { Mahyeldi- } \\
\text { Hendri Septa }\end{array}$ \\
\hline 1 & $\begin{array}{l}\text { Prod } \\
\text { uct } \\
\text { Polit } \\
\text { ic }\end{array}$ & $\begin{array}{l}\text { Sama- } \\
\text { sama di } \\
\text { dukung } \\
\text { oleh } \\
\text { koalisi } \\
\text { Partai } \\
\text { Politik } \\
\text { yang } \\
\text { memiliki } \\
\text { basis } \\
\text { suara } \\
\text { yang } \\
\text { cukup } \\
\text { banyak di } \\
\text { Kota } \\
\text { Padang }\end{array}$ & $\begin{array}{l}\text { Mengede } \\
\text { pankan } \\
\text { rekam } \\
\text { jejak } \\
\text { kandidat } \\
\text { sebagai } \\
\text { birokrat } \\
\text { dan } \\
\text { profesion } \\
\text { al, dan } \\
\text { menawar } \\
\text { kan } \\
\text { adanya } \\
\text { kemajuan } \\
\text { bagi Kota } \\
\text { Padang } \\
\text { melalui } \\
20 \\
\text { Program } \\
\text { unggulan } \\
\text { dan } \\
\text { terciptany } \\
\text { a } \\
\text { profesion } \\
\text { alitas } \\
\text { kerja di } \\
\text { lingkunga } \\
\text { n } \\
\text { Pemerint } \\
\text { ahan } \\
\text { Kota } \\
\text { Padang }\end{array}$ & $\begin{array}{l}\text { Mengedepank } \\
\text { an kandidat } \\
\text { sebagai politisi } \\
\text { yang sudah } \\
\text { bebrapa kali } \\
\text { memenangkan } \\
\text { pemilu dan } \\
\text { pilkada serta } \\
\text { mengedepanka } \\
\text { n keberhasilan } \\
\text { yang selama } \\
\text { ini sudah } \\
\text { dicapai, serta } \\
\text { figur kandidat } \\
\text { sebagai } \\
\text { seorang tokoh } \\
\text { agama, } \\
\text { berpendidikan } \\
\text { tinggi, ramah, } \\
\text { sederhana dan } \\
\text { konsisten } \\
\text { dengan janji } \\
\text { yang telah } \\
\text { disampaikan. }\end{array}$ \\
\hline
\end{tabular}

Volume 1 No. 32018

\begin{tabular}{|c|c|c|c|c|}
\hline 2 & $\begin{array}{l}\text { Plac } \\
\text { e } \\
\text { Polit } \\
\text { ic }\end{array}$ & $\begin{array}{l}\text { Sama- } \\
\text { sama } \\
\text { menggun } \\
\text { akan alat } \\
\text { peraga } \\
\text { kampaye, } \\
\text { memanfa } \\
\text { atkan } \\
\text { media } \\
\text { sosial, } \\
\text { media } \\
\text { massa } \\
\text { dan } \\
\text { media } \\
\text { cetak, } \\
\text { mendekat } \\
\text { i } \\
\text { masyarak } \\
\text { at pemilih } \\
\text { dengan } \\
\text { memposi } \\
\text { sikan diri } \\
\text { secara } \\
\text { baik } \\
\text { dengan } \\
\text { mereka. }\end{array}$ & $\begin{array}{l}\text { Melakuka } \\
\mathrm{n} \\
\text { kampany } \\
\text { e secara } \\
\text { langsung } \\
\text { ataupun } \\
\text { tidak } \\
\text { langsung } \\
\text { pada } \\
\text { masyarak } \\
\text { at, } \\
\text { melakuka } \\
\mathrm{n} \\
\text { berbagai } \\
\text { pendekat } \\
\text { an dan } \\
\text { berusaha } \\
\text { memposi } \\
\text { sikan diri } \\
\text { secara } \\
\text { baik } \\
\text { dihadapa } \\
\mathrm{n} \\
\text { masyarak } \\
\text { at } \\
\text { pemilih } \\
\text { sesuai } \\
\text { latar } \\
\text { belakang } \\
\text { masyarak } \\
\text { at } \\
\text { pemilih. }\end{array}$ & $\begin{array}{l}\text { Kemampuan } \\
\text { memposisikan } \\
\text { diri dihadapan } \\
\text { masyarakat } \\
\text { pemilih, } \\
\text { sehingga } \\
\text { masyarakat } \\
\text { berpandangan } \\
\text { mereka pantas } \\
\text { untuk menjadi } \\
\text { pemimpin } \\
\text { karena } \\
\text { mengerti } \\
\text { dengan } \\
\text { kebutuhan } \\
\text { masyarakat } \\
\text { dan Kota } \\
\text { Padang ke } \\
\text { depannya. }\end{array}$ \\
\hline 3 & $\begin{array}{l}\text { Pric } \\
\mathrm{e} \\
\text { Polit } \\
\text { ic }\end{array}$ & $\begin{array}{l}\text { Memaksi } \\
\text { malkan } \\
\text { pengguna } \\
\text { an dana } \\
\text { kampany } \\
\text { e untuk } \\
\text { segala } \\
\text { keperluan } \\
\text { selama } \\
\text { kampany } \\
\text { e dan } \\
\text { berusaha } \\
\text { mempro } \\
\text { mosikan } \\
\text { pasangan } \\
\text { calon } \\
\text { berdasark } \\
\text { an rekam } \\
\text { jejaknya } \\
\text { selama } \\
\text { ini dan } \\
\text { menampa } \\
\text { kan citra } \\
\text { positif } \\
\text { kepada } \\
\text { masyarak } \\
\text { at tentang }\end{array}$ & $\begin{array}{l}\text { Rekam } \\
\text { jejak } \\
\text { yang } \\
\text { ditonjolk } \\
\text { an } \\
\text { tentang } \\
\text { rekam } \\
\text { jejak } \\
\text { Emzalmi } \\
\text { dan Desri } \\
\text { sebagai } \\
\text { birokratd } \\
\text { an } \\
\text { profesion } \\
\text { al yang } \\
\text { tidak } \\
\text { memiliki } \\
\text { masalah } \\
\text { dalam } \\
\text { karirnya } \\
\text { selama } \\
\text { ini }\end{array}$ & $\begin{array}{l}\text { Menampakkan } \\
\text { rekam jejak } \\
\text { kedua } \\
\text { kandidat } \\
\text { sebagai } \\
\text { seorang } \\
\text { politisi dan } \\
\text { pemimpin yag } \\
\text { baik, } \\
\text { bijaksana, } \\
\text { ramah, religius } \\
\text { dan sederhana. }\end{array}$ \\
\hline
\end{tabular}




\begin{tabular}{|c|c|c|c|c|}
\hline & & $\begin{array}{l}\text { pasangan } \\
\text { calon }\end{array}$ & & \\
\hline 4 & $\begin{array}{l}\text { Pro } \\
\text { moti } \\
\text { on } \\
\text { Polit } \\
\text { ic }\end{array}$ & $\begin{array}{l}\text { Melakuka } \\
\mathrm{n} \\
\text { pendekat } \\
\text { an- } \\
\text { pendekat } \\
\text { an pada } \\
\text { masyarak } \\
\text { at dengan } \\
\text { berbagai } \\
\text { cara guna } \\
\text { menarik } \\
\text { simpati } \\
\text { berbagai } \\
\text { kalangan }\end{array}$ & $\begin{array}{l}\text { Kandidat } \\
\text { cendrung } \\
\text { mendekat } \\
\text { i } \\
\text { masyarak } \\
\text { at melalui } \\
\text { pendekat } \\
\text { an adat, } \\
\text { walaupun } \\
\text { dizaman } \\
\text { sekarang } \\
\text { hal } \\
\text { seperti itu } \\
\text { sudah } \\
\text { kurang } \\
\text { mendapat } \\
\text { perhatian, } \\
\text { selain itu } \\
\text { melakuka } \\
\mathrm{n} \\
\text { pendekat } \\
\text { an } \\
\text { kepada } \\
\text { anak } \\
\text { muda } \\
\text { dengan } \\
\text { cara } \\
\text { memberi } \\
\text { kan } \\
\text { suport } \\
\text { untuk } \\
\text { berbagai } \\
\text { kegiatann } \\
\text { ya, serta } \\
\text { mendekat } \\
\text { i } \\
\text { masyarak } \\
\text { at lain } \\
\text { melalui } \\
\text { kampany } \\
\text { e terbuka, } \\
\text { pembagia } \\
\text { n brosur, } \\
\text { pemasang } \\
\text { an alat } \\
\text { peraga, } \\
\text { kampany } \\
\text { e akbar } \\
\text { dan } \\
\text { sebagainy } \\
\text { a }\end{array}$ & $\begin{array}{l}\text { Kandidat } \\
\text { melakukan } \\
\text { pendekatan } \\
\text { pada semua } \\
\text { kalangan } \\
\text { masyarakat, } \\
\text { misalnya } \\
\text { menarik } \\
\text { simpati } \\
\text { pemuda } \\
\text { dengan ikut } \\
\text { berolahraga } \\
\text { bersama, } \\
\text { membenahi } \\
\text { karang taruna, } \\
\text { memberikan } \\
\text { pembelajaran } \\
\text { dan } \\
\text { merencanakan } \\
\text { Program } \\
\text { kampung } \\
\text { Pemuda (Pusat } \\
\text { kegiatan } \\
\text { pemuda) untuk } \\
\text { olahraga, seni } \\
\text { atau usaha. } \\
\text { Pendekatan } \\
\text { kepada PNS } \\
\text { dengan } \\
\text { menjanjikan } \\
\text { untuk } \\
\text { memberikan } \\
\text { jaminan hak } \\
\text { dengan tidak } \\
\text { menambah } \\
\text { kewajibannya, } \\
\text { sedangkan } \\
\text { untuk } \\
\text { masyarakat } \\
\text { menengah } \\
\text { kebawah } \\
\text { dengan } \\
\text { menjanjikan } \\
\text { adanya } \\
\text { perbaikan } \\
\text { jalan, } \\
\text { kemudahan } \\
\text { urusan dan } \\
\text { perizinan, } \\
\text { bantuan udaha } \\
\text { dan } \\
\text { sebagainya. }\end{array}$ \\
\hline
\end{tabular}

Sumber: Data primer.

\section{KESIMPULAN}

Marketing politik bagi setiap pasangan calon, tim sukses dan partai pendukung merupakan hal yang penting dilakukan dalam sebuah pesta demokrasi. Marketing politik yang dilakukan setiap pasang calon dalam Pilkada serentak Juni 2018 memiliki banyak persamaan, perbedaan, kelebihan dan kekurangan, jika dibandingkan berdasarkan political marketing, place political marketing, price political marketing, dan promotion political marketing. Berdasarkan perbandingan tersebut pasangan Mahyeldi-Hendri Septa terbukti unggul dari pada pasangan Emzalmi-Desri Ayunda setelah melakukan berbagai marketing politik selama masa kampanye. Marketing politik yang dilakukan MahyeldiHendri Septa ialah dengan mengedepankan keberhasilan yang telah dicapai pada periode sebelumnya disertai dengan adanya pendekatan-pendekatan khusus keberbagai kalangan masyarakat melalui kampanye-kampanye yang dilakukan. Platform partai pendukung juga menambah daya tarik masyarakat karena merupakan partai berideologi islam ditengah masyarakat Kota Padang yang mayoritas muslim. Penelitian ini diharapkan bisa menjadi sumbangan pemikiran yang berharga berupa khazanah ilmu pengetahuan tentang politik terutama marketing politik, dan juga bisa dijadikan referensi bagi peneliti selanjutnya yang juga akan meneliti hal terkait, serta bisa dijadikan bahan bacaan guna memperdalam ilmu pengetahuan. 


\section{DAFTAR PUSTAKA}

Damsar. 2015. Pengantar Sosiologi Politik. Jakarta : Prenadamedia Group.

Firmanzah. 2008. Marketing Politik. Jakarta: Yayasan Obor Indonesia

Sugiyono.2011. Metode Penelitian Pendidikan. Bandung:Alfabeta

Hamonangan, Gustiar. (2017). "Strategi Partai Keadilan Sejahtera (PKS) Untuk Memenangkan Calon Kepala Daerah yang Diusungnya di Kabupaten Padang Lawas Utara".Tazkir:Jurnal Pendidikan Ilmu-Ilmu Sosial dan Keagamaan Vol.3 No.2 Desember 2017 p-ISSN 24427004, e-ISSN 2460-609x.

Ramli, Lili. (2011). "Reformasi Partai Politik dan Sistem Kepartaian di Indonesia". Jurnal Politica Vol.2 No.2, November 2011.

Nurman,S, dan Al Rafni. 2005. "Strategi Partai Keadilan Sejahtera Kota Padang dalam Memenangkan Pemilu Legislatif 2004". Jurnal Demokrasi Vol. IV No. 2 Th.2005 Hal:61-76.

Purwaningsih,Titin. (2017). "Modalitas Calon Bupati Dalam Pemilihan Umum Kepala Daerah Tahun 2015" (Studi Kasus: Indah Putri Indriani Sebagai Bupati Terpilih di Kabupaten Luwu Utara Provinsi Sulawesi Selatan)". Journal of Governance And Public Policy. Vol.4 No.1 February 2017.

Pusida, Rianto. (2018). "Perilaku Pemilih Pada Pemilihan Umum Kepala Daerah Kabupaten Kepulauan Talaud Tahun 2013 (Studi
Volume 1 No. 32018

Tentang

Efektivitas

Kampanye)". Jural Jurusan Ilmu Pemerintahan, Vol.1. No. 1 Tahun 2018. ISSN: 2337-57736.

Rustandi, Dudi. (2013). "Pencitraan Politik Daring: Strategi Memenangkan Massa Digital Menjelang Pemilu 2014". Jurnal Observasi Vol.11 No.2 Tahun 2013.

Swasono, Yoga. 2017. "Pengaruh Alat Peraga kampanye Terhadap Partisipasi Politik di Kelurahan Sumber Rejo Pemilihan Kepala Daerah Bandar lampung 2015". Bandar lampung: Fakultas Ilmu Sosial dan Ilmu Politik, Universitas Lampung.

http://kota-padang.kpu.go.id/ diakses pada hari Minggu, 14 Juli 2019.

http://news.m.klikpositif.com/baca/34590/ fakta-di-balik-kekalahanemzalmi-desri-di-pilkadapadang?page $=3$ diakses pada hari Minggu, 14 Juli 2019

https://www.m.gosumbar.com/berita/baca/ 2016/02/27/kota-padang-kianmenawan-mahyeldi-emzalmiwujudkan-impian-masyarakat diakses pada hari Minggu, 14 Juli 2019 